\title{
Research Progress in Dynamics of Planetary Gear Transmission System
}

\author{
Jingyue Wang, Shibo Zhang, Haotian Wang
}

\begin{abstract}
In this paper, the research progress of dynamics of planetary gear transmission system is discussed. The dynamic model of planetary gear transmission system and the dynamic characteristics of planetary gear are elaborated emphatically. Three dynamic models of pure torsion, translation-torsion coupling and translation-torsion-axial coupling of planetary gear transmission system are introduced. The research progress of dynamic characteristics of planetary gear transmission system is described from three aspects: inherent characteristics, load sharing characteristics and dynamic response characteristics, and the future research is prospected.
\end{abstract}

Index Terms - Gear, Dynamics characteristics, Dynamics mode, Nonlinear dynamics.

\section{INTRODUCTION}

Gear transmission system is widely used in automobile, metallurgy, aviation, machinery, electronics, textile, mining and other fields [1 Liu Zhongming, Wang Changlu, Zhang Yuanguo, Zhang Liyong, Chen Guomin.]. With the continuous development of industrial technology, the requirements for the performance of gear transmission are becoming higher and higher. Compared with ordinary gear transmission, planetary gear transmission has many unique advantages. Its most obvious feature is that power can be diverted when transmitting power; at the same time, its input axis and output axis are coaxial, in other word, the axis of the output axis and the axis of the input axis are on the same axis. Therefore, planetary gears have been used to replace ordinary gears as transmission components, which are used in a variety of speed reducers, accelerators and other transmission devices. The planetary gear transmission system has the advantages of small size, small mass, strong bearing capacity, compact structure, large transmission ratio and smooth operation[2Wu Shijing, Ren Hui, Zhu Enyong]. As for the working state and structure of planetary gear transmission system are more complex than that of ordinary gear transmission system, the problems of noise and vibration are also relatively prominent [3Yang Fuchun, Zhu Xiaojun, Zheng Jinyang]. The efficiency of transmission, operation accuracy and service life of the equipment will also be affected to some extent.

For planetary gear transmission system, it is a multi-parameter excitation system. Its dynamic excitation includes stiffness excitation, error excitation and the excitation caused by gear meshing process. These excitation factors interact with each other, and the dynamic phenomena

Jingyue Wang, School of Automobile and Transportation, Shenyang Ligong University, Shenyang, China, State Key Laboratory of Mechanical Transmissions, Chongqing University,Chongqing, China

Shibo Zhang, School of Automobile and Transportation, Shenyang Ligong University, Shenyang, China

Haotian Wang, School of Automation, Shenyang Aerospace University, Shenyang, China caused by them are also very complex and rich. Thus, it can be seen that the dynamic modeling and dynamic characteristic analysis of planetary gear transmission system, the solution of dynamic response characteristics under different excitation factors, and the study of the influence of various parameters of the system on the dynamic characteristics are the focus of planetary gear transmission system dynamics research, which can provide theoretical basis and guidelines for optimization design, and have important theoretical and practical significance.

\section{RESEARCH STATUS OF DYNAMIC MODEL OF PLANETARY GEAR TRANSMISSION SYSTEM}

The research on the dynamics of planetary gear transmission system began in the 1970s. It is necessary to establish the planetary gear transmission model for studying the dynamic characteristics of planetary gear transmission system. At present, the main modeling methods for planetary gear include lumped parameter method and finite element method. The commonly used models in the dynamics research of planetary gear transmission system include pure torsion dynamics model, translation-torsion coupling dynamics model, and translation-torsion-axial coupling dynamics model [4Wang Jianjun,Li Runfang].

\section{A. Pure torsion dynamics model}

In 1994, Kahraman [5] respectively calculated the natural frequencies of the pure torsion model and the translation-torsion coupling model, and the difference between the two models was not significant. Therefore, when studying the dynamic response and stability of complex systems, some scholars choose to use pure torsion model to model planetary gear transmission system in order to simplify the model and reduce the amount of calculation. Parker et al. [6],[7],[8] studied the stability of single-stage planetary gear system with pure torsion model, analyzed the nonlinear effect, and solved the response of planetary gear system with euler method. In 2003, Sun and $\mathrm{Hu}$ [9] used pure torsion model to study the nonlinear dynamic characteristics of multi-clearance planetary gear transmission system. In 2005, Wang et al. [10] used pure torsion model to study the inherent characteristics and modal jump phenomena of planetary gear transmission system. In 2003, Sun et al. [11] established a clearance pure torsion non-linear dynamic model for $2 \mathrm{~K}-\mathrm{H}$ planetary gear mechanism considering the influence of backlash and time-varying meshing stiffness. The influence of comprehensive error excitation of gear pair on the non-linear dynamic characteristics of the system under external torque was studied by numerical integration method. In 2006, Song and $\mathrm{Xu}$ [12] established a modified torsion model of $2 \mathrm{~K}-\mathrm{H}$ planetary gear and studied its inherent characteristics. In 2007, Al-shyyab et al. [13] used harmonic balance method to 
solve the dynamic response of the system on the basis of pure torsion model. In 2014, Li and Zhu [14] used Poincaré mapping method to analyze the non-linear dynamic characteristics of planetary gear transmission system considering the influence of time-varying meshing stiffness, comprehensive transmission error and backlash.

\section{B. Translation-torsion coupling dynamics model}

In the planetary gear system, there are translational vibration among the components except torsional vibration. In 1994, Kahraman [15] considered the influence of time-varying meshing stiffness, comprehensive transmission error and backlash, established the translation-torsion coupling non-linear dynamic model of Spur Planetary gear transmission system, and analyzed the load-sharing characteristics of planetary gear. In 2003, Sun and Hu [16] considered the torsional displacement of planetary gear, gear ring and planetary frame, the torsional and transverse displacement of central solar wheel, and used the model to study the influence of time-varying meshing stiffness, error and backlash on the system's non-linear dynamic behavior. In 2010, Zhu et al.[17] established a translation-torsion coupled vibration model including friction force for $2 \mathrm{~K}-\mathrm{H}$ planetary gear system, and clearly pointed out that the vibration of the system would be aggravated due to the existence of friction force.

\section{Translation-torsion-axial coupling dynamics model}

In the actual process of planetary gear transmission, besides the translation and torsion vibration mentioned above, there will also be vibration in its axial direction. For the dynamic model of translation-torsion-axis coupling, there are more complex coupling vibration due to the large number of degrees of freedom. This model reflects the dynamic characteristics of helical planetary gear transmission system more comprehensively. However, due to the complexity of the model, it is difficult to solve and analyze the dynamic equation. In 1994, Kahraman [18] also considered the influence of the comprehensive transmission error on the system, simplified the time-varying meshing stiffness as fixed stiffness, ignored the rotation of the planetary frame, established the translation-torsion coupling dynamic model of the helical planetary gear, and discussed the phase tuning phenomenon. Eritenel and Parker [19] considered the flexibility of the input shaft and studied the free vibration characteristics of the system structure based on the model. Yang [20] used the model to derive the vibration equation of the system and analyze the free vibration characteristics of the system. Zhang and Liu [21] developed multi-body dynamics modeling and Simulation for helical planetary gear transmission. By comparing the simulation results with the previous conclusions, the correctness of the model is verified.

\section{RESEARCH STATUS OF DYNAMIC CHARACTERISTICS OF PLANETARY GEAR TRANSMISSION SYSTEM}

This paper describes the research status of dynamic characteristics of planetary gear transmission system from three aspects: inherent characteristics, load sharing characteristics and dynamic response characteristics.

\section{A. Inherent characteristics}

Inherent characteristics generally include natural frequencies and modes, which are the basic problems in the study of planetary gear dynamics. In 1974, Cunliffe, Smith and Welbourn [22] studied the characteristics of inherent frequencies and vibration modes of a 13-DOF planetary gear transmission system. In 1976, Botman [23] considered the influence of the speed of the planetary frame and the rigidity of the planetary wheel support on the inherent characteristics of the planetary gear mechanism, and studied the characteristics of the free vibration of the planetary gear mechanism by numerical method. In 1983, Prater et al. [24] further studied the inherent characteristics of the system when the support stiffness of planetary wheels is not equal, based on the research of Botman. In 1994, Kahraman [5] studied the inherent characteristics of the system by using pure torsion dynamics model of planetary gears. In 1999, Lin and Parker [25] studied the inherent characteristics of free vibration of planetary gear train with uniform planetary wheels. The results show that the vibration modes of the system can be divided into displacement mode, torsion mode and planetary wheel mode. In 2000, Lin and Parker [26] established the structural model of planetary gear transmission system with uneven distribution of planetary gears. On this basis, the free vibration characteristics of planetary gear transmission system with rotational symmetry structure were analyzed. It was found that the free vibration of planetary gear system could also be divided into the three vibration modes mentioned above. In 2005, Wang et al. [10] summarized the planetary wheel modal and torsion modal by using pure torsion dynamic model. The vibration characteristics of star gear in two modes are studied. By solving the sub-eigenvalue problem, the analytical expression of the natural frequency is obtained, and the sensitivity of the natural frequency to the parameters of the system is deduced. Parker et al. [27], [28] analyzed the inherent characteristics of planetary gear transmission based on the finite element model. In 2012, Yang [29] analyzed the frequency characteristics of the system considering the time-varying stiffness of the system. Considering the stiffness excitation, the vibration response of the system was analyzed, and the frequency domain characteristics of the system were obtained. In 2013, Qian et al. [30] analyzed the inherent characteristics of a planetary gear mechanism for mining machinery. In 2014, Zhang et al. [31] regarded the inner gear ring as an elastic continuum, and established a rigid-flexible coupling dynamic model of planetary transmission system with the flexible inner gear ring. Through theoretical analysis, four types of vibration modes of the system were revealed: torsional vibration mode of the central component, horizontal vibration mode of the central component, vibration mode of the planetary gear and vibration mode of the inner gear ring. The research shows that the flexibility of the gear ring reduces the natural frequencies of the lower modes of the system. In 2015, Liu and Zhang [32] established the translation-torsion coupling dynamic model of herringbone planetary transmission system and analyzed the inherent characteristics of the system, focusing on the modal transition phenomenon. In 2016, Xu et al. [33] studied the inherent characteristics of the planetary transmission system of wind turbines by translational-torsional dynamic model, focusing on the effects of support stiffness, internal and external meshing stiffness and torsional stiffness on the inherent characteristics of the system. The results show that the support stiffness of the sun gear, planetary gear and gear ring has a great influence on the lower natural frequencies of the system, while the support stiffness of the inner gear ring 
and the meshing stiffness of the inner gear ring have a great influence on the higher natural frequencies of the system. In 2018, Xia and Qin [34] verified the accuracy of the pure torsion model by studying the relationship between the resonance speed and the natural frequency of the system. In the same year, Wang et al. [35] solved the bending-torsion coupling dynamic model of planetary transmission by Newmark integral method, obtained the dynamic response of meshing force, and studied the influence of load change on the dynamic response.

\section{B. Load sharing characteristics}

The load sharing characteristic of planetary gears refers to the load distribution among planetary gears. It is very important to study the load sharing characteristics of planetary gears for their strength and reliability design. The study of load sharing characteristics of planetary gears began in the 1940s and 1950s. In 1986, Hidaka et al. [36] studied the relationship between eccentric error direction of planetary gear and load distribution through experiments. Since 1990s, NASA [37], [38],[39] began to study the load sharing characteristics of planetary gear transmission. In 1994, Kahraman [5] calculated the load sharing coefficient, and quantitatively analyzed the influence of system parameters, manufacturing and assembly errors on the load sharing coefficient. In 2000, Yuan et al. [40] found that reducing the supporting stiffness of the solar wheel appropriately is beneficial to reducing the meshing dynamic load and improving the dynamic balance of power diversion. In 2009, Lu et al. [41] studied the influence of various errors on the load-sharing characteristics of the system independently. The results show that the assembly errors and installation errors play a common role in the load-sharing characteristics of the system. During the period from 2009 to 2011, Kahraman et al. [42], Montestruc [43], Singh [44], [45] and others established different mathematical models of planetary gear transmission system, analyzed their load-sharing characteristics, and verified the accuracy of these models through finite element simulation calculation [42], [44], [45] and experiment [42]. Through these models, the load sharing of planetary gears can be predicted when they are designed. Based on the lumped parameter model, $\mathrm{Gu}$ and Velex analyzed the influence of position error [46] and eccentricity [47] on the uniform load characteristics of planetary gear system under dynamic load from 2012 to 2013. According to $\mathrm{Gu}$ and Velex's research results, it can be concluded that the conclusions of the load sharing characteristics of planetary gears under dynamic and quasi-static conditions are different for the position and eccentricity errors of pins. In 2014,Wang et al. [48] studied the multi-stage planetary gear system applied to wind power, and studied the influence of rotational speed and meshing error on the dynamic load of the system by numerical method. In 2015, Qiu et al. [49] studied the load sharing characteristics of planetary gear transmission based on lumped parameter model. In the same year, Hammami et al. [50] and others studied the influence of the meshing phase, position error of planetary gear and the mass factor of planetary frame on the load distribution characteristics of planetary transmission system. In 2016, Zhu et al. [51] established the dynamic differential equation of NGW type planetary transmission system considering the factors of micro-displacement, time-varying meshing stiffness and rotating damping of planetary frame, and focused on the analysis of the influence of the main support stiffness on the load-sharing characteristics of planetary transmission system. The results show that the load sharing performance will change rapidly in the sensitive region of the support stiffness, and the increase of the stiffness will deteriorate the load sharing performance of the system. In the same year, Li et al. [52] established the translation-torsion coupling dynamic model of two-stage planetary transmission system, and studied the influence of floating form of central component, planetary wheel error and coupling stiffness between stages on the load-sharing performance of the system. In 2017, Mutellip et al. [53] used contact-impact dynamics theory and rigid-flexible coupling modeling analysis method to calculate and analyze the distribution of meshing stress of planetary gear train, and then obtained the dynamic load-sharing coefficient under different torques. The dynamic load sharing coefficients of planetary gear trains and planetary wheels at different rotational speeds and torques are studied. The results show that the dynamic load sharing coefficient of planetary gear train decreases with the increase of rotational speed. In 2018, Zhang et al. [54] considered the time-varying meshing stiffness, eccentric error excitation of each component, floating of the central component and other factors, and solved the system load balance equation by Fourier series method, and qualitatively analyzed the influence of eccentric error of each component, floating mode of the central component, floating amount and torsional stiffness of flexible inner gear ring on the static load-sharing behavior of the system.

\section{Dynamic response characteristics}

The response of planetary gear transmission system under dynamic excitation is an important research content in the dynamics of planetary gear transmission system. The purpose of studying the dynamic response characteristics of the system is to reduce the dynamic excitation through system design modification, so as to reduce the vibration and noise of each part of the system. The dynamic characteristics of planetary gear transmission system are mainly affected by various non-linear factors. The following describes the research on the dynamic response characteristics of planetary gears from different non-linear factors.

Clearance is a strong non-linear factor, which has a great influence on the dynamic response characteristics of planetary gear transmission. In 1990, Blanche et al. [55] modeled the dynamic simulation of planetary transmission system on the basis of considering transmission error factors. The transmission response performance of the planetary transmission system was obtained by numerical analysis of tooth clearance and torque waveform by computer program. In 2001, Alshyyab and Kahraman [56] proposed models including time-varying meshing stiffness, clearance nonlinearity and transmission error, and analyzed the vibration stability, bifurcation and chaos of planetary gear train. In 2002, Sun and $\mathrm{Hu}$ [57] established the bending-torsion coupling vibration model of planetary gear transmission, and studied the influence of gear backlash on the amplitude-frequency characteristics of the system with gear meshing error and time-varying meshing stiffness. The results show that compared with linear systems, the dynamic characteristics of the system with clearance are obviously non-linear, and there are amplitude jumps and multi-value solutions, and the vibration of non-clearance components 
other than gear pairs can also present non-linear dynamic behavior. Sun et al. [16] established the bending-torsion coupling model of planetary gear with multi-clearance, time-varying meshing stiffness, transmission error and other factors in 2003, and analyzed the non-linear dynamic characteristics of planetary gear system by harmonic balance method. Ambarisha et al. [28] used lumped parameter model and finite element model to obtain complex non-linear dynamic response of Spur Planetary Gears in 2007. The jumping phenomenon, chaotic response and period doubling bifurcation were mainly analyzed. In the same year, Zhu et al. [58] took two-stage star gearbox as the research object. The meshing stiffness, backlash and transmission error were taken into account in the model. The non-linear dynamic equation under system excitation was established, and the way to chaotic road was analyzed. In 2011, Bahk et al. [8] established the pure torsion model of planetary gear transmission, and studied the non-linear dynamic response caused by gear-tooth separation by numerical method and analytical method. In 2012, Qin [59], [60], [61]considering the strong non-linear factor of backlash, obtained the dynamic response of wind turbine gearbox by numerical method. In the same year, Guo and Parker [62] established the lumped parameter model and finite element model of Planetary Gear Considering Bearing clearance, gear separation and time-varying meshing stiffness, and solved the dynamic response of the system by harmonic balance method combined with arc length continuation. In 2013, Lin et al. [63] established a non-linear model for cylindrical gear-spiral bevel gear-planetary gear transmission system, and further analyzed the influence of backlash and load torque on load bifurcation characteristics. In 2014, Li et al. [64] solved the dynamic differential equation with time-varying stiffness, transfer error, damping and backlash by Gill numerical method, and explored the influence of excitation frequency, damping and backlash on the periodic response of gear vibration mechanics. Based on the vibration mechanics model of planetary gear system. In 2015, Sheng [65] et al. considered the influence of backlash, stiffness and damping, and analyzed the influence of support stiffness, backlash and eccentricity error on the vibration state of this kind of transmission. Qin et al.[59], [60], [61], Chen et al. [66], [67], Mutellip et al. [68], [69], Qiu et al. [49], [70] all considered the influence of side clearance in the study of gear dynamics. In 2017, Zhu et al. [71] established the dimensionless motion differential equation of gear system based on Lagrange equation, solved the equation and obtained the results of non-linear dynamic response. The effects of excitation frequency, damping coefficient and backlash on the bifurcation and chaos characteristics of the system are obtained by means of dynamic bifurcation diagram, time history curve, phase trajectory and Poincaré diagram. In 2018, Xiang et al. [72] established a nonlinear torsion model of a multi-stage gear transmission system consisting of planetary gears with time-varying meshing stiffness, comprehensive error and multi-clearance and two-stage parallel gears. Nonlinear dynamic response is analyzed by using the reference value of backlash bifurcation parameters.

Friction is also a non-linear factor. During the operation of planetary gear transmission system, the magnitude and direction of friction force between gear pairs change periodically, forming an internal excitation, which is also an important excitation source of gear vibration. Many scholars have studied the gear dynamics model with friction force for the common fixed-shaft gear transmission system. As early as the late 1970s, Rao [73] explored the coupling characteristics between friction coefficient and tooth side clearance, and found that the change of tooth side clearance would affect friction coefficient. Five factors related to friction coefficient were analyzed. Based on the spur gear transmission system, Azar and Crossley [74] constructed the motion differential equation of this type of transmission, taking into account the influence factors such as time-varying meshing stiffness, tooth surface friction, gear tooth separation and gear modification, and analyzed the influence of parameters. In 2003, Vaishya et al. [75] studied the variation trend of friction under different working conditions of gear train, and compared the influence of linear tooth surface friction (time-varying and time-invariant) and friction on the vibration period of gear transmission system. In 2010, Cheng and Lie [76] based on the single-pair torsion model, solved the dynamic characteristics of tooth surface friction, meshing stiffness, tooth side clearance and other factors by using variable step Runge-Kutta numerical method, and explored the influence of friction on its dynamics. However, the research on planetary gears with friction was relatively late, and the related articles did not appear until 2010. In 2010, Zhu et al. [17] established a translation-torsion coupling nonlinear dynamic model of $2 \mathrm{~K}-\mathrm{H}$ planetary gear considering friction, time-varying meshing stiffness, backlash and comprehensive meshing error. The dynamic characteristics of the system were obtained by numerical solution. In 2012, Zhang [77] analyzed the meshing mechanism of single pair gear pairs, studied the influence of friction excitation, error excitation and slapping excitation on the non-linear vibration characteristics of the system, and carried out experimental verification. In 2015, Masoumi et al. [78] analyzed the contact of planetary gear pairs based on finite element method and obtained the time-varying meshing stiffness. Based on this, a translation-torsion dynamic model considering friction effect was established, and its solution results were compared with the classical literature to verify the correctness and reliability of the model. In the same year, $\mathrm{Lu}$ et al. [79] established the vibration model of double helical gear transmission, and explored the influence of friction effect on the vibration behavior of the transmission system. The results show that the inclusion of tooth surface friction can effectively suppress the chaotic state of the periodic response of the system and make the dynamic response of the system in quasi-periodic state. In 2015, Wang [80] studied the dynamic characteristics of the herringbone planetary gear transmission system with and without tooth surface friction. By comparing the periodic vibration responses of the system with and without tooth surface friction, the influence of tooth surface friction on the steady-state periodic response of the system was studied. The influence of tooth surface friction on the bifurcation and chaotic characteristics of the system was analyzed. In 2016, Chen et al. [65], aiming at the wind power planetary gear transmission system, according to the meshing characteristics of gears, systematically analyzed and deduced the friction arm of each meshing tooth surface when the sun gear, planetary gear, inner gear ring, planetary gear single and double teeth meshed. Based on the mixed elastohydrodynamic lubrication model, the friction between the meshing surfaces was analyzed. A multi-degree-of-freedom lumped-parameter nonlinear 
dynamic model of translation-torsion coupling is established, which includes mixed elastohydrodynamic lubrication friction, time-varying meshing stiffness, transmission error and backlash. The numerical results show that as an internal parameter excitation, friction increases the vibration of the system along the meshing line; compared with boundary lubrication, hybrid elastohydrodynamic lubrication can reduce the vibration of the system. Experiments show that the model can predict the non-linear dynamic characteristics of wind power planetary gears very well. In 2017, Chen et al. [81] established a coupled torsional dynamic model for the second-stage planetary gearbox, taking into account the factors of tooth surface friction, time-varying stiffness and inter-stage coupling. The vibration responses under different friction coefficients are solved. The analysis results show that the friction force on the tooth surface has an impact on the accuracy of the dynamic model, which lays a foundation for the fine dynamic modeling and structural optimization of the multi-stage planetary gear transmission system. In the same year, Chen [82] based on the multi-stage planetary gear transmission system, considered the calculation method of the friction force and friction coefficient of the tooth surface, which laid the foundation for the fine dynamic modeling and structural optimization of the multi-stage planetary gear transmission system. In 2017, TU and Yuan [83] aimed at the large error in the transmission process of wind power helical planetary gear train, considered the influence of multiple clearances and frictions on gear meshing, and used the explicit algorithm to solve the impact stress of solar gear in the planetary gear system under different loads.

The fault of planetary gear is also a non-linear factor. Many scholars have studied the dynamic model of gear with faults in common fixed-axis gear transmission system. In 1996, Choy et al. [84] simulated the pitting corrosion and wear of tooth surface through experiments. In 2001, Badaoui et al.[85] created a fault gear model with partial flaking of gear teeth, and used Cepstrum to judge the fault of gear. In the same year, Bartelmus [86] studied gearbox fault diagnosis by establishing mathematical model and computer simulation technology . Litak and Friswell [87] studied the influence of tooth profile defects on gear meshing stiffness in 2005. Wu et al. [88] established a lumped parameter model of a pair of gears in 2008, and used the model to analyze the effect of root cracks on the dynamic response of gear system. In 2009, Chaari et al. [89] established a finite element model, and obtained a more accurate mathematical model of spur gears with crack faults. In 2012, Omar et al. [90] obtained the influence of root crack on the dynamic response of gear through the experimental study of root crack. However, the current research on planetary gears with faults is relatively rare and relatively late, until about 2012, the relevant articles were seen. From 2012 to 2013, Gu and Velex [46], [47] studied the influence of eccentric fault of planetary gears on the dynamic response of the system. The results show that the planetary gear is more sensitive to eccentricity than the general fixed-axis gear transmission system. For planetary gear trains with dynamic loads, more complex modulation side-band responses will result.. In 2013, Feng et al. [91], [92] established vibration signal models of planetary gearbox in normal state, distributed fault state and partial fault state. Through experiments, the frequency domain characteristics of planetary gearbox in normal state, distributed fault state and local fault state are obtained. Many gear faults can be attributed to meshing stiffness faults. In 2014, Litak [93] studied the dynamic characteristics of gear transmission system when meshing stiffness faults existed. For planetary gear system, Liang and Zuo [94] deduced the time-varying meshing stiffness of the system under crack failure. Chen and Shao [95]studied the dynamic response of planetary gear transmission system with root cracks in inner gear ring. The fault response characteristics of planetary gears with root cracks in flexible inner ring are analyzed [96 Chen Z, Zhu Z, Shao Y]. In 2015, Ma et al. [97] systematically summarized and summarized the research progress of the dynamics of gear transmission system with cracks . In 2015, Chen [98] using three-dimensional modeling software Pro/E established planetary gear tooth broke, pitting corrosion and crack fault model, and then by dynamic simulation software for the platform, the different gear in planetary gear train of multi-body dynamics simulation on different fault, the fault model simulation of meshing force characteristics compared with theory analysis, illustrate the use of virtual prototype technology of fault simulation, the feasibility of gear transmission system. In 2016, Lei et al. [99] considered the effect of time-varying vibration transmission path on vibration response, established the corresponding dynamic model, solved the dynamic response of planetary gear train under normal, crack and spalling conditions, and analyzed their spectrum characteristics. By comparing and analyzing the test signal with the model response signal, the accuracy of the dynamic model is verified. In the same year, Gui et al. [100] built a dynamic model with various manufacturing errors. In the model, the influence of faults on the time-varying meshing stiffness and transmission errors was considered after the occurrence of crack faults. The envelope spectrum structure characteristics of planetary gear, solar gear and gear ring faults and normal gear system were compared by simulation, and the characteristic frequency of faults was summarized. Gao [101] used the energy method to calculate the meshing stiffness of gears in 2016. Combining with the characteristics of typical damage of gears, the effects of root cracks, tooth missing and pitting damage on the time-varying meshing stiffness of gears were analyzed and studied. In 2017, Li [102] established a fault planetary gear train dynamic model considering the damage degree of key components, and analyzed its vibration characteristics under damage excitation accurately. On this basis, the mechanism of generation and evolution of planetary gear train faults was revealed, which can provide effective support for early fault diagnosis of planetary gear box, and has important theoretical significance and engineering value. In 2018, Shi et al. [103] established the dynamic model of planetary gear train, taking into account the time-varying effect of vibration transmission path on vibration signal during operation; deduced the expression of meshing stiffness variation under planetary gear fault, and introduced fault factors to obtain meshing stiffness under different fault degrees; solved the dynamic model of planetary gear train by Runge-Kutta method with variable step size. The spectrum characteristics of the system response are obtained when the planetary gear has cracks and broken teeth respectively.

\section{SUMMARY AND PROSPECT}

In this paper, the research status of dynamics of planetary gear transmission system is expounded, and the research 
status of dynamics model and system dynamics characteristics of planetary gear system are expounded respectively. The dynamic models are described from three aspects: pure torsion dynamic model, translation-torsion coupled dynamic model and translation-torsion-axial coupled dynamic model. The study of dynamic characteristics is described from three aspects: inherent characteristics, load sharing characteristics and dynamic response characteristics. In the description of dynamic response characteristics, three non-linear factors, clearance, friction and fault, are elaborated respectively.

There is still much work to be done to study the dynamics of planetary gears.

(1)The establishment and solution of the complex dynamic model of translation-torsion-axial coupling should become a problem to be discussed. In practical application, the axial vibration of planetary gear transmission system will also occur, so the axial vibration should be minimized.

(2)There are many non-linear factors in the process of planetary gear transmission. In addition to the three mentioned in this paper, there are also factors such as eccentric mass of gears and different lubrication modes between gears. The influence of non-linear factors on the dynamics of planetary gears can still be used as the future research direction.

(3) In the existing research, the fixed-axle gear is the main research object, and the research on the dynamics of the backlash of the planetary gear system is very little, and the complete planetary gear box including gears, shafts, bearings and so on is not taken as the analysis object.

(4) In the existing research, the research on the influence of friction on planetary gears is not enough and abundant, so it is still necessary to discuss the influence of friction on planetary gears.

(5) In the existing research, the impact of fault on planetary gears is not enough and abundant, so it is still necessary to discuss the impact of fault on planetary gears.

\section{ACKNOWLEDGMENT}

The authors gratefully acknowledge the support of project funded by the China Postdoctoral Science Foundation (2017M610496), State Key Laboratory of Mechanical Transmissions (SKLMT-KFKT-201605) and Natural Science Foundation of Liaoning Province of China (20170540786).

\section{REFERENCES}

[1] Liu Zhongming,Wang Changlu,Zhang Yuanguo,Zhang Liyong,Chen Guomin. "Status, Challenge and the Vision in 2030 of China Gear Industry" Journal of Mechanical Transmission, Vol.35, December 2011, pp1-6.

[2] Wu Shijing, Ren Hui, Zhu Enyong,et al. "Research advances for dynamics of planetary gear trains" Engineering Journal of Wuhan University, March 2010, pp398-403 .

[3] Yang Fuchun,Zhou Xiaojun,Zheng Jinyang. "Dynamic model and vibration characteristics of complex compound planetary gear set " Journal of Vibration and Shock. Vol30, August 2011,pp144-148.

[4] Wang Jianjun,Li Runfang."The Theoretical System of the Gear Vibration Theory" China Mechanical Engineering,Vol9, December 1998, pp55-58.

[5] Kahraman A. "Natural modes of planetary gear trains" Journal of sound and vibration,Vol73, January 1994,pp125-130.

[6] Lin J, Parker R G. “ Planetary gear parametric instability caused by mesh stiffness variation" Journal of Sound and vibration, Vol249, January 2002, pp129-145.

[7] Canchi S V, Parker R G. "Effect of ring-planet mesh phasing and contact ratio on the parametric instabilities of a planetary gear ring" Journal of Mechanical Design, Vol130,January 2008, pp14501.
[8] Bahk C J, Parker R G. "Analytical solution for the nonlinear dynamics of planetary gears" Journal of Computational and Nonlinear Dynamics, Vol6, February 2011, pp21007.

[9] Sun T, Hu H. "Nonlinear dynamics of a planetary gear system with multiple clearances" Mechanism and Machine Theory, Vol38, December 2003, pp1371-1390.

[10] Wang Shiyu, Song Yimin, Shen Zhaoguang, et al. "Research on natural characteristics and loci veering of planetary gear transmissions "Journal of Vibration Engineering, April 2005, pp 412-417.

[11] Sun Zhimin, Ji Linhong, Shen Yunwen. "Nonlinear dynamics of 2K-H planetary gear train" Journal of Tsinghua University (Science and Technology), May 2003, pp636-639.

[12] Song Yimin, Xu Weidong. "Modified torsional model development and natural characteristics analysis of $2 \mathrm{k}-\mathrm{h}$ epicyclic gearing" Chinese Journal of Mechanical Engineering, Vol42, May 2006, pp16-21.

[13] Al-shyyab A, Kahraman A. "A non linear dynamic model for planetary gear sets" Proceedings of the Institution of Mechanical Engineers, Part K: Journal of Multi-body Dynamics, Vol221, 2007, pp567-576.

[14] Li T, Zhu R. "Global Analysis of a Planetary Gear Train" Shock and Vibration, 2014, pp1-6.

[15] Kahraman A. "Load sharing characteristics of planetary transmissions" Mechanism and Machine Theory, Vol 29, August 1994, pp1151-1165.

[16] Tao Sun, Hai Yan Hu. "Nonlinear dynamics of a planetary gear system with multiple clearances" Mechanism and Machine Theory, Vol38, 2003, pp1371-1390.

[17] Zhu Enyong,Wu Shijing,Wang Xiaosun,et al. "Study on nonlinear dynamic model of planetary gear train sets with friction force" Journal of Vibration and Shock, August 2010, pp217-220.

[18] Kahraman A. "Planetary gear train dynamics" Journal of Mechanical design, Vol116, March 1994, pp713-720.

[19] Eritenel T, Parker R G. "Modal properties of three-dimensional helical planetary gears" Journal of Sound and Vibration, Vol 325 , January 2009, pp397-420.

[20] Yang Tongqiang."A study on dynamics of helical planetary gear train" Tianjin:Tianjin University, 2004.

[21] Zhang Jun, Liu Xian-zeng. "Multibody dynamic modeling and analysis for a helical planetary gear train" Journal of Vibration and Shock, Vol33, July 2014, pp11-17.

[22] Cunliffe F, Smith J D, Welboum D B. "Dynamic tooth loads in epicyclic gears" Journal of Engineering for Industry,Vol94, 1974,pp578-584.

[23] Botman M. "Epicycilc gear vibration" Journal of Engineering for Industry, Vol96, 1976, pp811-815.

[24] Prater J L, August R, Oswald F B. "Vibration in planetary gear systems with unequal planet stiffnesses" NASA Technical Memorandum, 1983:83428.

[25] Lin J, Parker R G. "Analytical characterization of the unique properties of planetary gear free vibration" Journal of Vibration and Acoustics. Transactions of the ASME, Vol16, 1999, pp316-322.

[26] Lin J, Parker R. "Structured vibration characteristics of planetary gears with unequally spaced planets" Journal of Sound and Vibration, Vol233 May 2000, pp921-928.

[27] Parker R G, Agashe V, Vijayakar S M. "Dynamic Response of a Planetary Gear System using a Finite Element/Contact Mechanics Model" Journal of Mechanical Design, Vol122, March 2000, pp304-310.

[28] Ambarisha V K, Parker R G. "Nonlinear dynamics of planetary gears using analytical and finite element models" Journal of sound and vibration, Vol302, March 2007, pp577-595.

[29] Yang Jun. "Study on Dynamics Characteristics of Planetary Gear Transmission System of Wind Turbine under Varying Loads" Chongqing University, 2012.

[30] Qian P, Zhang Y, Cheng G. "Model analysis and verification of $2 \mathrm{~K}-\mathrm{H}$ planetary gear system" Journal of Vibration and Control, 2013.

[31] Zhang Jun, Liu Xianzeng, Jiao Yang, Song Yimin. "Vibration Analysis of Planetary Gear Trains Based on a Discrete continuum Dynamic Model” Journal of Mechanical Engineering, Vol15, 2014, pp104-112.

[32] Liu Zhenzhou Zhang Jun. "Analysis of Natural Characteristic and Loci Veering/Crossing of Double Helical Planetary Gear Train” Journal of Mechanical Transmission, October 2015,pp9-15.

[33] Xu Huachao, Sun Wenlei, Zhou Jianxing, Chen Haixia. "sensitivity of planetary gear natural characteristics used in wind turbine" Acta Energiae Solaris Sinica, January 2016, pp201-207.

[34] Xia Yangzhiqiang, Qin Datong. "Natural characteristics and vibration of a high-speed-ratio planetary gear transmission with low-loss gears" 
Journal of Vibration and Shock, Vol37, February 2018, pp242-247+260.

[35] Wang Yaxin, Hu Mingjian, Li Chenyang. "Analysis of Inherent Characteristics and Dynamic Response of Planetary Gear Transmission System" Hoisting and Conveying Machinery, No.518, April 2018, pp114-119.

[36] Hidaka Teruaki, Yamamoto Nobuyuki, Ishida Takeshi. "Relation between Various Errors and Load Distribution in Load-sharing Mechanism of Planetary Gear Device" Transactions of the Japan Society of Mechanical Engineers(C), Wang Liyan, translate, Vol52, 1986, pp2200-2206.

[37] Kishj G, Sikorsky. "Aircraft advanced rotorcraft transmission (ART)pr ogram-final report" NASA CR-191079, NASA Lewis Research Center, 1993.

[38] Timothy L Krantz, Irebert R Delgado. "Experimental study of split-path transmission load sharing" NASA Technical Memorandum 107202, 1996.

[39] Timothy L Krantz. "A method to analyze and optimize the load sharing of split path transmissions" NASA Technical Memorandum 107201, 1996.

[40] Yuan Ru, Wang Sanmin, Shen Yunwen. "Dynamic Optimum Design of Power Shared out Equally Among the Planetary Gears" Journal of Aerospace Power,Vol15,April 2000,pp410-412.

[41] Lu Junhua, Zhu Rupeng, Jin Guanghu. "Analysis of Dynamic Load Sharing Behavior in Planetary Gearing" Journal of Mechanical Engineering, Vol45, May 2009, pp85-90.

[42] Ligata H, Kahraman A, Singh A. "A closed-form planet load sharing formulation for planetary gear sets using a translational analogy" Journal of Mechanical Design, Vol131, February 2009,pp 21007

[43] Montestruc A N. "A Numerical Approach to Calculation of Load Sharing in Planetary Gear Drives" Journal of Mechanical Design, Vol132, January 2010, pp14503.

[44] Singh A. "Load sharing behavior in epicyclic gears: Physical explanation and generalized formulation" Mechanism and Machine Theory, Vol 45, March 2010, pp511-530.

[45] Singh A. "Epicyclic load sharing map - development and validation" Mechanism and Machine Theory, Vol46, May 2011, pp632-646.

[46] Gu X, Velex P. "A dynamic model to study the influence of planet position errors in planetary gears" Journal of Sound and Vibration, Vol331, 2012, pp4554-4574.

[47] Gu X, Velex P. "On the dynamic simulation of eccentricity errors in planetary gears" Mechanism and Machine Theory, Vol61, 2013, pp14-29.

[48] Wang J, Wang Y, Huo Z. "Analysis of dynamic behavior of multiple-stage planetary gear train used in wind driven generator" Scientific World Journal, 2014, 627045.

[49] Qiu X, Han Q, Chu F. "Load-sharing characteristics of planetary gear transmission in horizontal axis wind turbines" Mechanism and Machine Theory,Vol92, 2015, pp391-406.

[50] Hammami A., Santamaria M.I., Del Rincon A.F., Chaari F., Rueda F.V., Haddar M.(2015)“ Load Sharing Behavior in Planetary Gear Set”. In:Haddar M.et al.(eds) Multiphysics Modelling and Simulation for Systems Design and Monitoring. Applied Condition Monitoring, vol 2. Springer, Cham.

[51] Zhu Zengbao, Jiang Zhixiang, Yin Min. "Impact of support stiffness on dynamic load sharing characteristics of planetary train system ”Journal of Aerospace Power, April 2016, pp986-992.

[52] Li Siqian, Wu Shijing, Wang Xiaosun. "Analysis of the Dynamic Load Sharing Characteristic of Two - stage Planetary Transmission" Journal of Mechanical Transmission, October 2016,pp11-16+27.

[53] Zhang Linlin, Zhu Rupeng. "Static load sharing behavior of herringbone planetary gear train with floating composite ring gear" Journal of Central South University(Science and Technology),Vol49, May 2018.

[54] D.C.H.Yang, J.G.Blanche. "Design and application guidelines for cycloid drives with machining tolerances" Mechanism and Machine Theory, Vol 5, May 1990, pp487-501.

[55] Kahraman A. "Free torsional vibration characteristics of compound planetary gear sets" Mechanism and Machine Theory, Vol36, 2001 , pp953-971.

[56] Sun Tao, Hu Haiyan."Nonlinear dynamics of planetary gear transmission by harmonic balance method based on DFT" Journal of Mechanical Engineering, Vol38, November 2002, pp58-61.

[57] Zhu Zibing, Zhu Rupeng, Bao Heyun. "Non-linear dynamic study of 2-stage star gear train" Journal of Aerospace Power, Vol22, November 2007, pp1963-1970.
[58] Zhou Zhigang, Qin datong,Yang Jun,et al. "Gear-bearing coupling dynamics characteristics of wind turbine planetary gear transmission system under variable load" Journal of Chongqing University, December 2012, pp7-14

[59] Qin Datong, Tian Miaomiao, Yang Jun. "Study on dynamic characteristics of gear transmission system of wind generator under varying wind load" Acta Energiae Solaris Sinica, February 2012, pp190-196.

[60] Qin Datong, LI Chao, TANG Feixiong. "Study on dynamic characteristics of gear transmission system of variable speed wind generator under varying wind load" Acta Energiae Solaris Sinica, Vol34, February 2013, pp186-195.

[61] Guo Y, Parker R G. "Dynamic analysis of planetary gears with bearing clearance" Journal of Computational and Nonlinear Dynamics, Vol7, April 2012, pp41002.

[62] Lin Tengjiao, Wang Danhua, Ran Xiongtao, et al. "Coupled nonlinear vibration analysis of a multi-stage gear transmission system" Journal of Vibration and Shock, Vol32, 2013, pp1-7.

[63] Li S, Wu Q, Zhang Z. "Bifurcation and chaos analysis of multistage planetary gear train" Nonlinear Dynamics, Vol75, January 2014, pp217-233.

[64] Sheng D P, Zhu R P, Jing G H,et al. "Dynamic load sharing behavior of transverse-torsional coupled planetary gear train with multiple clearances" Journal of Central South University, Vol22, July 2015 , pp2521-2532.

[65] Chen Changzheng, Zhang Lei, Liu Jie,et al. "Dynamic model of wind turbine planetary gear set with mixed elastohydrodynamic lubrication friction force" Acta Energiae Solaris Sinica, July 2016, pp1695-1701.

[66] Chen Changzheng, Zhang Lei,Liu Jie,et al. "Nonlinear dynamic response analysis of planetary set of wind turbine gaerbox considering backlash" Acta Energiae Solaris Sinica, June 2016, pp1587-1593.

[67] Mutellip Ahmat, Huo Zhongtang, Zhao Yang. "Analysis of dynamic load sharing characteristics of planetary gear system for wind turbine" Acta Energiae Solaris Sinica, February 2017, pp492-497.

[68] Huo Zhongtang, Mutellip Ahmat, Zhao Yang. "Study for transmission characteristics of wind turbine planetary gear system" Acta Energiae Solaris Sinica, November 2016, pp2814-2820.

[69] Mutellip Ahmat, Chen Yuxiang. "Nonlinear modeling and analysis for planetary gear system with multi-gap meshing impact of wind turbine" Acta Energiae Solaris Sinica, December 2016, pp3163-3169.

[70] Qiu Xinghui, Han Qinkai, Chu Fulei. "Influence of pitching base motion on the planetary gear in wind turbines" Journal of Vibration Engineering, June 2016, pp945-953.

[71] Zhu W, Wu S, Wang X, et al. "Bifurcation and Chaos Analysis of Compound Planetary Gear Sets" International Symposium on Computational Intelligence \& Design. IEEE, 2017.

[72] Xiang L, Zhang Y, Gao N, et al."Nonlinear Dynamics of a Multistage Gear Transmission System with Multi-Clearance" International Journal of Bifurcation \& Chaos, 2018.

[73] Rao A C. "The correction of gear friction coefficients for backlash" Wear, Vol47, January 1978,pp1-4.

[74] Azar R C, Crossley F R E. "Digital simulation of impact phenomenon in spur geared system" ASME Englnd, Vol99, 1977, pp792-798.

[75] Vaishya M, Singh R, Vaishya M, et al. "Strategies for Modeling Friction in Gear Dynamics” Journal of Mechanical Design, Vol125, Febuary 2003, pp383-393.

[76] Cheng Z G and Lie C. "Effects of teeth surface friction on the vibration of gear transmission in Mechanical and Electronics Engineering", 2010 2nd International Conference on ICMEE, IEEE, 2010.

[77] Zhang Jing. "Simulation and Experimental Research on Gear Transmission Dynamics with Various Excitation Factors" Chongqing:Chongqing University, 2012.

[78] Masoumi A, J Pellicano F, Samani F S, et al. "Symmetry breaking and chaos-induced imbalance in planetary gears" Nonlinear Dynamics, Vol80, January 2015, pp561-582.

[79] Lu F, Zhu R, Wang H, et al. "Dynamic Characteristics of Double Helical Planetary Gear Train With Tooth Friction" ASME 2015 International Design Engineering Technical Conferences and Computers and Information in Engineering Conference. American Society of Mechanical Engineers, 2015:V010T11A028 -V010T11A028

[80] Wang Haofei. "Dynamic Analysis of the Double Helical Planetary Gear Trains considering Tooth Friction" Nanjing University of Aeronautics and Astronautics, 2015.

[81] Chen Fu, Xiao Zhengming, Huan Lirong. "Dynamic Modeling and Analysis of 2-stage Planetary Gear Transmission System Including Friction" Machine Design \& Research, Vol33, January 2017, pp63-66+71. 
[82] Chen Fu. "Nonlinear Dynamic Modeling and Analysis of Multi-stage Planetary Gear Transmission System" Kunming University of Science and Technology, 2017.

[83] Tu Xueying, Yuan Liang. "Non-linear Dynamic Modeling and Dynamic Incentive Analysis of Gear Meshing for Wind Turbine Gear System" Modular Machine Tool \& Automatic Manufacturing Technique, July 2017, pp45-49.

[84] F.K.Choy, J V.Polyshchuk, J.J.Zakrajsek, et al. "Analysis of the effects of surface pitting and wear on the vibrations of a gear transmission system.” Tribology International, Vol29, January 1996, pp71-83.

[85] M.El Badaoui, J.Antoni, F.Guillet and J. Daniere. "Use of the moving cepstrum integral to detect and localize tooth spalls in gears." Mechanical Systems and Signal Processing, Vol15, May 2001, pp873-885.

[86] W.Bartelmus. "Mathematical modeling and computer simulations as an aid to gearbox diagnostics" Mechanical Systems and Signal Processing, Vol15, May 2001, pp855-871.

[87] G.Litak, M.I.Friswell. "Dynamics of a gear system with faults in mesh stiffness" Nonlinear Dynamics, Vol 41, 2005, pp415-421.

[88] S.Wu, M.J.Zuo, A.Parey. "Simulation of spur gear dynamics and estimation of fault growth" Journal of Sound and Vibration, Vol317, 2008, pp608-624.

[89] F.Chaari, T.Fakhfakh, M.Haddar. "Analytical model of spur gear tooth crack and influence on gear mesh stiffness" European Journal of Mechanics A/Solids, Vol28, 2009, pp461-468.

[90] F.K.Omar, K.A.Moustafa and S.Emam. "Mathenatical modeling of gearbox including defects with experimental verification" Journal of Vibration and Control, Vol18, September 2012, pp1310-1321.

[91] Feng Zhipeng, Chu Fulei. "Vibration Spectral Characteristics of Distributed Gear Fault of Planetary Gearboxes" Proceedings of the CSEE, February 2013, pp118-125.

[92] Feng Zhipeng, Zhao Leilei, Chu Fulei. "Vibration Spectral Characteristics of Localized Gear Fault of Planetary Gearboxes" Proceedings of the CSEE, May 2013, pp119-127.

[93] Litak G, M I F. "Dynamics of a Gear System with Faults in Meshing Stiffness" Nonlinear Dynamics, Vol41, April 2004, pp415-421.

[94] Liang X, Zuo M J, Pandey M. "Analytically evaluating the influence of crack on the mesh stiffness of a planetary gear set" Mechanism and Machine Theory, Vol 76, 2014, pp20-38.

[95] Chen Z, Shao Y. "Dynamic simulation of planetary gear with tooth root crack in ring gear" Engineering Failure Analysis, Vol 31, 2013, pp 8-18.

[96] Chen Z, Zhu Z, Shao Y. "Fault feature analysis of planetary gear system with tooth root crack and flexible ring gear rim" Engineering Failure Analysis, Vol 49, 2015, pp92-103.

[97] Ma H, Zeng J, Feng R, et al. "Review on dynamics of cracked gear systems" Engineering Failure Analysis, Vol 45, 2015, pp 224-245.

[98] CHEN Tao. "Simulation and Analysis on Dynamic Characteristics for Gearbox Drive System of Wind Turbine" North China Electric Power University, 2015.

[99] Lei Yaguo, Luo Xi, Liu Zongrao, et al. "A New Dynamic Model of Planetary Gear Sets and Research on Fault Response Characteristics" Journal of Mechanical Engineering, 2016, pp111-122.

[100]Gui Yong, Han Qinkai, Li Zheng,et al. "The Fault Diagnosis of Cracks in the Planetary Gear System of Wind Turbine" Journal of Vibration, Measurement \& Diagnosis, January 2016, pp169-175.

[101]Gao Guojian. "Study on Dynamic Modeling and Analysis for Damaged Planetary Gear Train” North China Electric Power University, 2016.

[102]Li Guoyan. "Research on Damage Modeling and Fault Diagnosis of the Compound Planetary Gear System" Shan Dong University, 2017.

[103]Shi Lichen, Li Kun, Wang Haitao. "Fault response characteristics of tractor planetary gearbox based on dynamical simulation and its validation" Transactions of the Chinese Society of Agricultural Engineering, Vol 34, July 2018, pp66-74. 